\title{
Pushing Past the 'Too Hard Basket'
}

New Zealand Journal of Teachers' Work, Volume 11, Issue 2, 166-169, 2014

\author{
SUE STOVER \\ Auckland University of Technology
}

The New Zealand Herald's recent alarmist headlines would not surprise anyone active in early childhood education (ECE.). That the sector includes poor quality centres is well known. What is also not surprising is that the politicians are unable to address the structural issues involved, because they are intractable. The early childhood sector has been built up on the back of regulations that are clearly unsatisfactory for children's well-being, but to change them disrupts other agendas-such as protecting the investments made both by commercial and not-for-profit operators; investments in buildings, for starters. If, as the Education Review Office says, the child is 'at the heart of the matter', then children's well-being needs to foregrounded by politicians and the disruption to 'business as usual' needs to be well signalled and managed. As many in the sector have repeatedly advised the Ministry of Education, change is needed to lift the minimum adult:child ratio for those children under two years old (see for example, Carroll-Lind \& Angus, 2011). That it remains at 1:5 is arguably tantamount to institutional child abuse, especially for babies. While most centres manage to offer more satisfactory ratios, there are many who operate at the minimum standards. Stress levels are high in such centres-for teachers and for children. While teachers can resign, infants and toddlers have few choices except to cry. Research into the impact of stress points to the release of the hormone cortisol; this has long term implications for infants' brains. Importantly, it is babies that have amongst the longest number of hours in ECE each week (Dalli, White, Rockel \& Duhn, 2011).

Group size also needs to be reduced. When licensing criteria changed in 2011, the maximum group size increased to (in theory) as many as 150 in a group. The then Minister of Education, Anne Tolley, indicated that parents would be able to pick and choose the best centres; in other words that the marketplace would ensure that children were in appropriately sized groups. This is fine in theory, and especially in situations where parents have a choice of centres and when they are confident and informed enough to discern how centres run. However, there are centres which run with children in very large groups. Who is responsible for children's well-being in centres where the minimum requirements are met, but their well-being is clearly not being met?

The government is to be congratulated for inching up the weeks available for paid parental leave; we have now made it to 16 weeks. But the length of paid parental leave needs to keep increasing towards and beyond 6 months. Criticism of the early childhood sector can undermine its credibility and add to the stress of any family with a young baby as they navigate their way through the complexity of early parenting. This raises ethical dilemmas for those who want to enable families to have confidence in choosing to combine parenting 
with employment. How to advocate for change without demonising hard working centre-based teachers and their management? How to acknowledge problems without placing more pressure on parents to take on the burden of fully discerning what is quality ECE for their smallest children? As I have been reminded by an advocate for quality infant and toddler ECE, 'We don't want to dump on mothers and make them feel guilty in choosing not be at home full time with their very young children'.But we can't escape economic drivers for ECE. This is especially true in the context of places such as Auckland where two incomes are seen as basic to any family paying the cost of living within an overheated housing market.

The conversation needs to continue about what it means to put children 'at the heart of the matter', but it is a conversation that needs to move beyond chatter, rhetoric and alarmist media reports. It needs to gain political traction. It needs recognition of employers about their importance in supporting the complexity of issues that confront the parents of young children.

In addition, the rhetoric of "choice-which underpins much of the logic of ECE provision-needs to be upheld in policy. Those services which are framed around parents choosing to stay involved with their children and their communities, are the services which are shrinking in enrolment numbers (Education Counts, 2013). Their demise could reduce parental 'choice' to an unpalatable array of options. 


\section{REFERENCES}

Carroll-Lind, J. \& Angus, J. (2011). Through their lens: An inquiry into non parental education and care of infants and toddlers. Wellington: Children's Commissioner. Available from http://www.occ.org.nz/assets/Uploads/Reports/Education/Through-theirlens.pdf

Dalli, C., White, E.J., Rockel, J. \& Duhn, I. (2011). Quality early childhood education for under-two-year-olds: What should it look like? A literature review. Report to Ministry of Education. Available from http://www.educationcounts.govt.nz/publications/ECE/Quality ECE for un der-two-year-olds/executive-summary

Education Counts. (2013). Annual ECE census: Report 2013. Available from https://www.educationcounts.govt.nz/statistics/early-childhoodeducation/annual-ece-summary-reports 


\section{ABOUT THE AUTHOR}

\section{SUE STOVER}

Auckland University of Technology

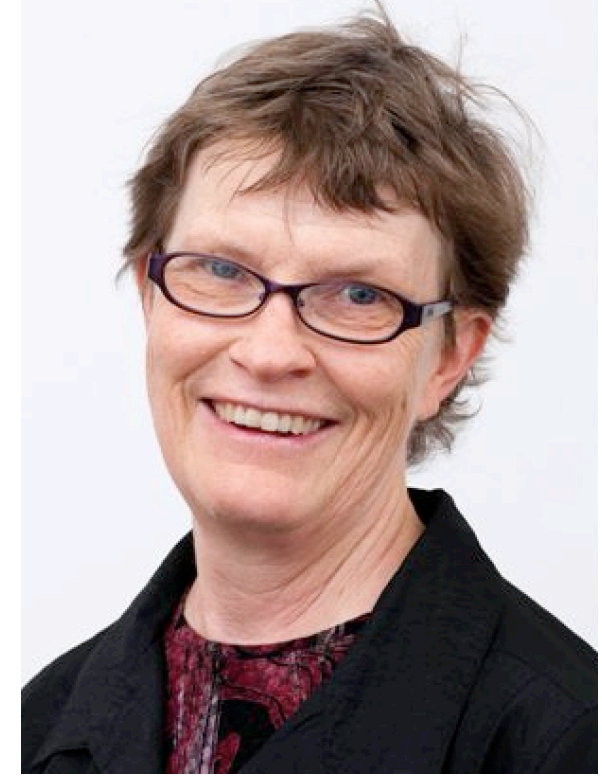

Sue Stover's interest in early childhood education began in Aotearoa New Zealand's parent co-operative Playcentre which she attended alongside her three young sons in the 1980s and 1990s. Sue Stover is an editor of Early Education, and Programme Leader for the Early Childhood at AUT University, Auckland, New Zealand.

Contact: Sue.stover@aut.ac.nz 